\title{
BMJ
}

\section{Epidemiology of rib fractures in older men: Osteoporotic Fractures in Men (MrOS) prospective cohort study}

\author{
Elizabeth Barrett-Connor, distinguished professor and chief, ${ }^{1}$ Carrie M Nielson, assistant professor, ${ }^{2}$ Eric \\ Orwoll, professor, ${ }^{2}$ Douglas C Bauer, professor, ${ }^{3}$ Jane A Cauley, professor, ${ }^{4}$ for the Osteoporotic Fractures in \\ Men (MrOS) Study Groupfor the Osteoporotic Fractures in Men (MrOS) Study Group
}

1Department of Family and Preventive Medicine, University of California, San Diego, 9500 Gilman Drive, La Jolla, CA 92093-0607, USA

${ }^{2}$ Bone and Mineral Unit, Oregon Health and Science University, Portland, OR 97239-3098, USA

${ }^{3}$ General Internal Medicine, University of California, San Francisco, CA 94107, USA

${ }^{4}$ Department of Epidemiology, University of Pittsburgh, Pittsburgh, PA 15241, USA Correspondence:EBarrett-Connor ebarrettconnor@ucsd.edu

Cite this as: BMJ 2010;340:c1069 doi:10.1136/bmj.c1069

\section{ABSTRACT}

Objective To study the causes and consequences of radiologically confirmed rib fractures (seldom considered in the context of osteoporosis) in community dwelling older men.

Design Prospective cohort study (Osteoporotic Fractures in Men (MrOS) Study).

Setting and participants 5995 men aged 65 or over recruited in 2000-2 from six US sites; 99\% answered mailed questionnaires about falls and fractures every four months for a mean 6.2 (SD 1.3) year follow-up.

Main outcome measures New fractures validated by radiology reports; multivariate Cox proportional hazard ratios were used to evaluate factors independently associated with time to incident rib fracture; associations between baseline rib fracture and incident hip and wrist fracture were also evaluated.

Results The incidence of rib fracture was 3.5/1000 person years, and $24 \%(126 / 522)$ of all incident non-spine fractures were rib fractures. Nearly half of new rib fractures ( $48 \%$; $n=61$ ) followed falling from standing height or lower. Independent risk factors for an incident rib fracture were age 80 or above, low bone density, difficulty with instrumental activities of daily living, and a baseline history of rib/chest fracture. Men with a history of rib/chest fracture had at least a twofold increased risk of an incident rib fracture (adjusted hazard ratio 2.71, $95 \%$ confidence interval 1.86 to 3.95$)$, hip fracture (2.05, 1.33 to 3.15$)$, and wrist fracture $(2.06,1.14$ to 3.70$)$. Only $14 / 82$ of men reported being treated with bone specific drugs after their incident rib fracture.

Conclusions Rib fracture, the most common incident clinical fracture in men, was associated with classic risk markers for osteoporosis, including old age, low hip bone mineral density, and history of fracture. A history of rib fracture predicted a more than twofold increased risk of future fracture of the rib, hip, or wrist, independent of bone density and other covariates. Rib fractures should be considered to be osteoporotic fractures in the evaluation of older men for treatment to prevent future fracture.

\section{INTRODUCTION}

Little has been written about the causes and consequences of rib fractures. Most of the early literature on rib fracture was based on small studies of patients in hospital or institutions. ${ }^{12}$ A community based study from Australia found that rib fractures were the most common non-spine fractures in elderly people. ${ }^{3}$ National hospital registry data from Finland showed that rates of rib fracture resulting from minimal trauma increased between 1970 and 2001 and that rates more than doubled after age 80 and were higher in men than in women. ${ }^{4}$

A large community dwelling cohort in Europe included men and women (mean age: men, 64.2; women, 63.6) who were followed for incident fractures for three years by an annual postcard query. ${ }^{5}$ In this relatively young cohort, only $135(2.3 \%)$ of 6344 men and $101(1.6 \%)$ of 6788 women reported a history of rib fracture at baseline. A history of rib fracture predicted a significantly increased risk of any new fracture, including hip fracture, in women but not in men.

The aim of our study was to characterise the epidemiology of rib fractures in older community dwelling men to determine whether these fractures are likely to be osteoporotic fractures, with similar risk factors and prognostic implications. We used data from the Osteoporotic Fractures in Men (MrOS) Study, a prospective study of 5995 community dwelling men aged 65 and older from six geographical locations in the United States. Incident fractures were ascertained every four months, with a $99 \%$ response rate from surviving participants for a mean of 6.2 (SD 1.3) years, and were verified by radiology reports.

In this report, we compare the baseline characteristics and bone mineral density among men who had a new rib fracture with those without a new rib fracture; determine which of these characteristics were associated with an incident rib fracture; compare the independent predictive association of the baseline rib fracture history and the baseline bone mineral density with any new non-spine fracture and with incident fracture of the rib, hip, and wrist; and describe the reported circumstances leading to the new rib fracture and prescribing of osteoporosis drugs after the incident rib fracture. 
Table 1|Characteristics of 5879 men aged 65 and over with and without incident rib fracture (MrOS Study). Values are numbers (percentages) unless stated otherwise

\begin{tabular}{|c|c|c|c|}
\hline Characteristics & $\begin{array}{l}\text { No incident rib } \\
\text { fracture }(n=5753)\end{array}$ & $\begin{array}{l}\text { Incident rib fracture } \\
\quad(n=126)\end{array}$ & Pvalue* \\
\hline \multicolumn{4}{|l|}{ Age (years): } \\
\hline $65-69$ & $1714(29.8)$ & $36(29)$ & \multirow{4}{*}{0.08} \\
\hline 70-74 & $1652(28.7)$ & $27(21)$ & \\
\hline $75-79$ & $1384(24.1)$ & $31(25)$ & \\
\hline$\geq 80$ & $1003(17.4)$ & $32(25)$ & \\
\hline \multicolumn{4}{|l|}{ Clinic site: } \\
\hline Birmingham & $939(16.3)$ & $13(10)$ & \multirow{6}{*}{0.1} \\
\hline Minneapolis & $973(16.9)$ & $17(13)$ & \\
\hline Palo Alto & $944(16.4)$ & $30(24)$ & \\
\hline Pittsburgh & $974(16.9)$ & $20(16)$ & \\
\hline Portland & $967(16.8)$ & $26(21)$ & \\
\hline San Diego & $956(16.6)$ & $20(16)$ & \\
\hline \multicolumn{4}{|l|}{ Race/ethnicity: } \\
\hline White & $5138(89.3)$ & $118(94)$ & \multirow{5}{*}{0.4} \\
\hline Black & $240(4.2)$ & $2(2)$ & \\
\hline Asian & $184(3.2)$ & $4(3)$ & \\
\hline Hispanic & $121(2.1)$ & $2(2)$ & \\
\hline Other & $70(1.2)$ & 0 & \\
\hline Married & $4739(82.4)$ & $103(82)$ & 0.9 \\
\hline College graduate & $3060(53.2)$ & $61(48)$ & 0.3 \\
\hline \multicolumn{4}{|l|}{ Overall health†: } \\
\hline Very poor to fair & $806(14.0)$ & $16(13)$ & \multirow{2}{*}{0.7} \\
\hline Good or excellent & $4945(86.0)$ & $110(87)$ & \\
\hline \multicolumn{4}{|l|}{ Body size: } \\
\hline Mean (SD) height (cm) & $174.2(6.8)$ & $173.1(6.6)$ & 0.07 \\
\hline Mean (SD) weight (kg) & $83.3(13.3)$ & $80.7(12.9)$ & 0.03 \\
\hline Mean (SD) body mass index $\left(\mathrm{kg} / \mathrm{m}^{2}\right)$ & $27.4(3.8)$ & $26.9(3.9)$ & 0.1 \\
\hline Mean (SD) weight change since age $25(\mathrm{~kg})$ & $10.4(11.4)$ & $10.0(11.2)$ & 0.6 \\
\hline Mean (SD) height at age $25(\mathrm{~cm})$ & $177.9(6.9)$ & $177.6(6.6)$ & 0.6 \\
\hline Mean (SD) total hip bone mineral density $\left(\mathrm{g} / \mathrm{cm}^{2}\right)$ & $0.96(0.14)$ & $0.91(0.14)$ & $<0.0001$ \\
\hline Mean (SD) total hip bone mineral density t score & $-0.55(0.97)$ & $-0.94(0.96)$ & $<0.0001$ \\
\hline \multicolumn{4}{|l|}{ Alcohol use in past yeart: } \\
\hline None & 2027 (35.3) & $47(37)$ & \multirow{3}{*}{0.6} \\
\hline 1-7 drinks/week & $2723(47.4)$ & $54(43)$ & \\
\hline$>7$ drinks/week & $995(17.3)$ & $25(20)$ & \\
\hline \multicolumn{4}{|l|}{ Smokingt: } \\
\hline Ever & $3587(62.4)$ & $85(67)$ & \multirow{2}{*}{0.2} \\
\hline Never & 2165 (37.6) & $41(33)$ & \\
\hline Mean (SD) pack years & $28.9(25.6)$ & $30.4(27.4)$ & 0.8 \\
\hline
\end{tabular}

* $P$ values are for differences in rib fracture case status by $x^{2}$ or Fisher's exact test for categorical variables, two sided $t$ tests for normally distributed continuous variables, and Wilcoxon rank-sum test for skewed continuous variables.

†Numbers in the "No incident rib fracture" column do not total to 5753 owing to a small number of missing values. within a geographical area, and few exclusions were made. Participants were recruited from drivers' license lists, voter registration lists, and Medicare data, as well as convenience samples from advertisements and mailers to age specific demographics. Recruitment of ethnic minorities was enhanced through the use of the Health Care Financing Administration and other databases that allowed for targeted recruitment. Response to mass mailings at some sites surpassed 10-15\%, and appointment attendance rates averaged above $85 \%$.

Eligibility criteria were the ability to walk without the assistance of another person and no bilateral hip replacements. All participants provided written informed consent. Details of the MrOS study design, recruitment, and baseline cohort characteristics have been described. ${ }^{67}$

For the analysis presented here, we excluded all participants who reported baseline use of bisphosphonates, calcitonin, fluoride, raloxifene, or testosterone injections used by men who had a history of osteoporosis $(n=115)$. After exclusion of one additional participant who had missing follow-up data, $5879(98 \%)$ men with baseline data remained for this analysis. The mean follow-up time was 6.2 (SD 1.3) years, and the final data collection for this paper was completed in January 2008.

\section{Measures}

We used self administered questionnaires at baseline to ascertain each participant's demographic and lifestyle information and their personal and family medical history. Interviews or examinations by trained study staff members included measures of functional status; anthropometric data; and cognitive, visual, and neuromuscular function. ${ }^{7}$

Baseline questionnaires asked about age, race/ethnicity, marital status, education, perceived relative socioeconomic status, ${ }^{8}$ and overall health. We assessed physical activity by using the physical activity scale for the elderly. ${ }^{9}$ Fracture history included questions on personal or parental history of osteoporosis or fracture, location of fracture, and whether the fracture occurred at age 50 or older. History of rib, chest, or sternum fracture was a single question; because sternum fracture is rare and rib and chest fracture are the same, we refer to the baseline rib/chest/sternum fracture rate as the baseline rib fracture rate. At baseline, participants reported whether they had fallen in the previous 12 months, and we assessed functional status by summing the amount of difficulty, on a 0-3 scale, with five instrumental activities of daily living - walking on level ground, climbing steps, preparing meals, housework, and shopping.

The Block 98 semi-quantitative food frequency questionnaire (Block Dietary Data Systems, Berkeley, CA) was modified for MrOS to capture the most important sources of calcium, vitamin $\mathrm{D}$, and other nutrients associated with osteoporosis in older men in the United States..$^{10}$ We evaluated intake of calcium (mg) and vitamin D (IU) from diet and supplements, after excluding responses from men who reported were enrolled in the study at six clinical centres: Birmingham, AL; Minneapolis, MN; the Monongahela Valley near Pittsburgh, PA; Palo Alto, CA; Portland, OR; and San Diego, CA. As reported elsewhere, ${ }^{6}$ potential participants were community dwelling 
Table 2 | Medical history of 5879 men aged 65 and over with and without incident rib fracture (MrOS Study). Values are numbers (percentages) unless stated otherwise

\begin{tabular}{|c|c|c|c|}
\hline Medical history & $\begin{array}{l}\text { No incident rib fracture } \\
\qquad(\mathrm{n}=5753)\end{array}$ & $\begin{array}{l}\text { Incident rib fracture } \\
\qquad(n=126)\end{array}$ & P value* \\
\hline Fracture at or after age 50 & $1246(21.7)$ & $50(40)$ & $<0.001$ \\
\hline Rib fracture & $819(14.2)$ & $41(33)$ & $<0.001$ \\
\hline Rib fracture at or after age 50 & $398(6.9)$ & $17(13)$ & 0.004 \\
\hline Maternal history of fracture & $1264 / 4077(31.0)$ & $27 / 77$ (35) & 0.4 \\
\hline Paternal history of fracture & $873 / 3225(27.1)$ & $17 / 63(27)$ & 0.99 \\
\hline Maternal history of osteoporosis & $445 / 3579(12.4)$ & $7 / 68$ (10) & 0.6 \\
\hline Paternal history of osteoporosis & $42 / 3666(1.2)$ & $1 / 77$ (1) & 0.9 \\
\hline \multicolumn{4}{|l|}{ Ever had: } \\
\hline Diabetes & $620(10.8)$ & $17(13)$ & 0.3 \\
\hline Low thyroid function & $394(6.9)$ & $10(8)$ & 0.6 \\
\hline Osteoporosis & $113(2.0)$ & $6(5)$ & 0.03 \\
\hline Stroke & $326(5.7)$ & $9(7)$ & 0.5 \\
\hline Heart attack & $803(14.0)$ & $19(15)$ & 0.7 \\
\hline Hypertension & $2496(43.4)$ & $50(40)$ & 0.4 \\
\hline Chronic obstructive pulmonary disease & $604(10.5)$ & $13(10)$ & 0.9 \\
\hline Parkinson's disease & $45(0.8)$ & $3(2)$ & 0.08 \\
\hline Angina & $818(14.2)$ & $23(18)$ & 0.2 \\
\hline Congestive heart failure & $305(5.3)$ & $7(6)$ & 0.9 \\
\hline Prostatitis & $1430(24.9)$ & 37 (29) & 0.2 \\
\hline Arthritis & $2731(47.5)$ & $47(37)$ & 0.02 \\
\hline Cancer & $1650(28.7)$ & $46(37)$ & 0.06 \\
\hline Kidney stones & $752(13.1)$ & $18(14)$ & 0.7 \\
\hline Any falls in previous year & $1189(20.7)$ & 37 (29) & 0.02 \\
\hline
\end{tabular}

*For differences in rib fracture case status by $x^{2}$ or Fisher's exact test for categorical variables, two-sided $t$ test for normally distributed continuous variables, and Wilcoxon rank-sum test for skewed continuous variables.

intake of less than $400 \mathrm{kcal}(1.67 \mathrm{MJ})$ a day. Participants also reported tobacco use (current, past, or never) and alcohol use (drinks per week). Participants were asked to bring in all prescription and non-prescription drugs used within the previous 30 days. We used a computerised dictionary, based on the original Established Populations for Epidemiologic Studies of the Elderly coding system, ${ }^{11}$ to categorise drugs. All recorded prescription drugs were stored in an electronic drugs inventory database (San Francisco Coordinating Center, San Francisco, CA). We matched each drug to its ingredient(s) on the basis of the Iowa Drug Information Service Drug Vocabulary (College of Pharmacy, University of Iowa, Iowa City, IA).

We measured height $(\mathrm{cm})$ on Harpenden stadiometers and weight $(\mathrm{kg})$ on calibrated standard balance beam or digital scales. We calculated body mass index as $\mathrm{kg} / \mathrm{m}^{2}$. Areal bone mineral density was measured for the total hip and spine by using fan beam dual energy $x$ ray absorptiometry (QDR 4500W, Hologic, Bedford, MA) at all study sites. Participants were scanned according to standardised procedures, scanners were calibrated at baseline, and daily quality control scans showed no shifts in scanner performance at any site during the enrolment period.

Participants were asked to attempt three neuromuscular function tests: chair stand, narrow walk, and grip strength. They were asked to stand from a chair without using their arms; those who were unable to do a single chair stand were classified as "unable" to complete the test. All men who were able to complete the single chair stand were asked to complete the repeated chair stand test. The ability and time needed to complete five stands without using the arms were recorded. Men who were unable to do five chair stands without using their arms or refused were also classified as "unable." Participants were asked to complete a narrow walk trial over a $20 \mathrm{~cm}$ wide, $6 \mathrm{~m}$ course; each participant was asked to attempt two trials. A third trial was requested if the participant deviated at least twice during either trial. Inability to complete any of these trials successfully was recorded. Grip strength $(\mathrm{kg})$ was measured twice by a handheld dynamometer (Jamar Hydraulic Hand Dynamometer, Sammons Preston, Bolingbrook, IL) in both the right and left arms; we used the average of right and left hand in the analysis.

\section{Fracture reporting}

We ascertained incident fractures with triannual questionnaires delivered by mail or telephone. Study staff followed up reports of fracture to determine the date, trauma, and other circumstances that preceded the fracture. We collected narrative reports of circumstances preceding the fracture. We categorised degree of trauma by the height from which the participant had fallen (standing height or less; on stairs, steps, or kerb; or from more than standing or stairs/step height) or by degree of trauma (minimal, moderate, or severe). Study physicians centrally adjudicated fractures through medical records and radiological reports; we included all confirmed rib fractures except those classified as pathological (cancer metastases) in this analysis. Because exclusion of traumatic fractures has been reported to underestimate the contribution of osteoporosis to fractures in women and men, ${ }^{12}{ }^{13}$ we did not exclude such fractures from this analysis.

\section{Statistical analysis}

We compared baseline characteristics between participants with and without incident rib fracture during the follow-up period by using $\chi^{2}$ or Fisher's exact test for categorical variables, two sided $t$ tests for normally distributed continuous variables, and Wilcoxon rank-sum

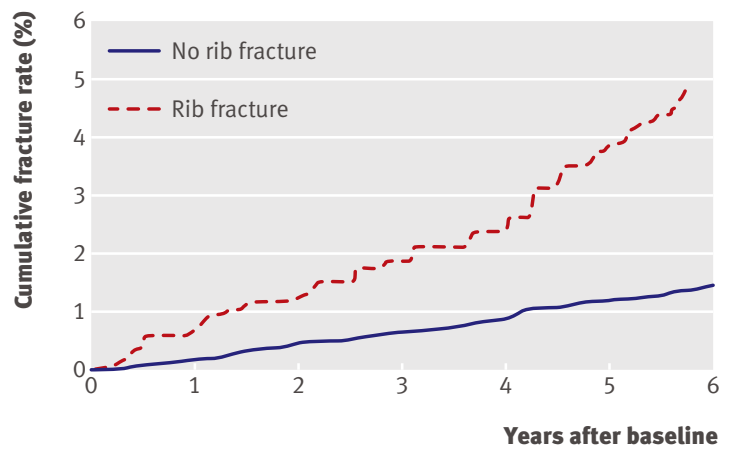

Fig 1 1 Cumulative incidence of rib fracture among men with and without baseline history of rib fracture $(n=5879)$, MrOS Study 
Table $3 \mid$ Neuromuscular, mental, and physical functioning of 5879 men aged 65 and over with and without incident rib fracture (MrOS Study). Values are numbers (percentages) unless stated otherwise

\begin{tabular}{|c|c|c|c|}
\hline Measure & $\begin{array}{l}\text { No incident rib fracture } \\
\qquad(n=5753)\end{array}$ & $\begin{array}{l}\text { Incident rib fracture } \\
\qquad(n=126)\end{array}$ & P value* \\
\hline \multicolumn{4}{|l|}{ Neuromuscular function: } \\
\hline $\begin{array}{l}\text { Inability to rise from chair without using } \\
\text { arms } 5 \text { times }\end{array}$ & $123(2.1)$ & $3(2)$ & 0.8 \\
\hline $\begin{array}{l}\text { Inability to successfully complete any } \\
\text { narrow walk trials }\end{array}$ & $525(9.1)$ & $12(10)$ & 0.9 \\
\hline \multicolumn{4}{|l|}{ Grip strength† (quarters): } \\
\hline Unable, refused & $108(1.9)$ & $1(1)$ & \multirow{5}{*}{0.05} \\
\hline $1: 7-32 \mathrm{~kg}$ & $1336(23.2)$ & $42(33)$ & \\
\hline $2: 33-38 \mathrm{~kg}$ & $1403(24.4)$ & $31(25)$ & \\
\hline 3: $39-43 \mathrm{~kg}$ & $1432(24.9)$ & $21(17)$ & \\
\hline 4: $44-66 \mathrm{~kg}$ & $1473(25.6)$ & $31(26)$ & \\
\hline $\begin{array}{l}\text { Mean (SD) SF12 modified mental summary } \\
\text { score }\end{array}$ & $55.6(7.0)$ & $55.9(7.2)$ & 0.6 \\
\hline $\begin{array}{l}\text { Mean (SD) SF12 modified physical summary } \\
\text { score }\end{array}$ & $49.0(10.2)$ & $48.1(10.7)$ & 0.3 \\
\hline \multicolumn{4}{|l|}{$\begin{array}{l}\text { Physical activity scale for the elderly score } \dagger \\
\text { (quarters): }\end{array}$} \\
\hline 1:0-99 & $1417(24.6)$ & $32(25)$ & \multirow{4}{*}{0.7} \\
\hline $2: 100-141$ & $1440(25.0)$ & $29(23)$ & \\
\hline 3: $142-186$ & $1451(25.2)$ & $28(22)$ & \\
\hline $4: 187-486$ & $1442(25.1)$ & 37 (29) & \\
\hline \multicolumn{4}{|l|}{ Daily sitting time (hours): } \\
\hline$\ll 1$ & $168(2.9)$ & $4(3)$ & \multirow{4}{*}{$>0.99$} \\
\hline $1-2$ & $1137(19.8)$ & $24(19)$ & \\
\hline $2-4$ & $2765(48.1)$ & $59(47)$ & \\
\hline$\geq 4$ & $1683(29.3)$ & $39(31)$ & \\
\hline Difficulty with 5 IADLs (mean (SD) score) & $0.53(1.45)$ & $0.86(1.97)$ & 0.005 \\
\hline
\end{tabular}

IADLs=instrumental activities of daily living.

*For differences in rib fracture case status by $x^{2}$ or Fisher's exact test for categorical variables, two sided $t$ tests for normally distributed continuous variables, and Wilcoxon rank-sum test for skewed continuous variables. †Numbers in the "No incident rib fracture" column do not total to 5753 owing to a small number of missing values.

test for skewed continuous variables. We included men with fractures at locations other than the rib in the analysis as non-cases. We calculated incidence of rib fracture as cases per 1000 person years. We further evaluated characteristics that were associated with rib fracture $(\mathrm{P}<0.10)$ in Cox proportional hazard models of the time to first rib fracture. We tested the validity of the proportional hazards assumption. We found a nonlinear association with age (men aged 80 or above were at highest risk), so we used a dichotomous age variable in subsequent analyses.

We generated dichotomous variables from neuromuscular function tests for inability to rise from a chair five times without using the arms and for inability to successfully complete any narrow walk trials. We categorised grip strength into quarters, with a separate category for participants who refused or were unable to complete the test. The purpose of this was to minimise the number of participants considered to have missing data while still providing an indicator of neuromuscular function.

To identify the set of factors independently associated with rib fracture, we developed a multivariable adjusted Cox proportional hazards model. We entered potential risk factors that were statistically significant $(\mathrm{P}<0.10)$ in age adjusted models into stepwise models, using a $\mathrm{P}<0.10$ criterion for each variable to be added to the model and a $\mathrm{P}<0.05$ criterion for the variable to be kept in the model after subsequent variables were added. Because several factors were correlated, we did a variance inflation factor test for multicollinearity among all variables. Variance inflation factor tests for all variables were between 1.01 and 2.10 , indicating no multicollinearity. We constructed models by using the stepwise procedure without excluding and after excluding bone mineral density. In another analysis, we included bone mineral density in the stepwise procedure to determine whether including bone mineral density influenced the selection of other variables into the model. We used a Cox regression model for all time to event analyses and adjusted comparisons of baseline history of rib fracture as a determinant of future clinical fractures. To assess the association between history of rib fracture and occurrence of other major incident fractures, we calculated the adjusted hazard ratios for any fracture and for wrist and hip fracture, using the same multivariate model that we constructed for incident rib fracture. Finally, we did two sensitivity analyses to determine whether associations differed when other (non-rib) fractures were excluded from the non-case group and when all self reported rib fractures (not only adjudicated fractures) were included in the case group. We used SAS version 9.1 for all analyses.

\section{RESULTS}

Almost a quarter (24\%) of all 522 confirmed non-spine fractures that occurred during the follow-up period were confirmed rib fractures; 126 men reported a new rib fracture that was confirmed by radiology report as a non-pathological (non-metastatic cancer related) fracture, an incidence of 3.5 per 1000 person years. Rib fractures were the most common non-spine fractures. Figure 1 shows the greater cumulative incidence of fracture among men with a baseline history of rib fracture than in those with no such history.

Tables 1, 2, 3, and 4 show the characteristics of the 5753 men who did not have an incident rib fracture and the 126 men who did have an incident rib fracture. At baseline, men who subsequently had a rib fracture were older, weighed less, had lower bone mineral density of the hip and spine, and were more likely to have a history of fracture (rib or any site), to have fallen in the past year, and to have difficulties with instrumental activities of daily living and poor grip strength (tables 1 , 2, and 3). Overall, 860 men had a history of rib fracture at baseline (table 2).

As also shown in table 2 , men with an incident rib fracture were somewhat more likely to have a personal history of osteoporosis $(\mathrm{P}=0.03)$, cancer $(\mathrm{P}=0.06)$, or Parkinson's disease $(\mathrm{P}=0.08)$ and less likely to have a history of arthritis $(\mathrm{P}=0.02)$. Among drugs used by at least $10 \%$ of men, $\alpha$ blocker and statins were the only ones even marginally associated with incident rib fracture status ( $\alpha$ blocker $21 \%$ of cases $v 15 \%$ of non-cases, 
Table $4 \mid$ Drug use, depression, and calcium and vitamin D intake of 5879 men aged 65 and over with and without incident rib fracture (MrOS Study). Values are numbers (percentages) unless stated otherwise

\begin{tabular}{lccc}
$\begin{array}{l}\text { Characteristics } \\
\text { Drug use: }\end{array}$ & $\begin{array}{c}\text { No incident rib fracture } \\
(\mathrm{n}=5753)\end{array}$ & $\begin{array}{c}\text { Incident rib fracture } \\
(\mathrm{n}=126)\end{array}$ & P value* $^{*}$ \\
\hline Loop diuretic & $277(4.8)$ & $5(4)$ & 0.8 \\
\hline SSRI & $150(2.6)$ & $6(5)$ & 0.1 \\
\hline Tricyclic antidepressant & $93(1.6)$ & $4(3)$ & 0.1 \\
\hline Thyroid hormone & $375(6.5)$ & $12(10)$ & 0.2 \\
\hline a blocker & $866(15.1)$ & $26(21)$ & 0.08 \\
\hline Androgen & $25(0.4)$ & $0(0)$ & $>0.99$ \\
\hline ACE inhibitor & $1036(18.0)$ & $22(17)$ & 0.9 \\
\hline Benzodiazepine & $164(2.9)$ & $6(5)$ & 0.2 \\
\hline$\beta$ blocker & $1013(17.6)$ & $20(16)$ & 0.6 \\
\hline Statins & $1482(25.8)$ & $40(32)$ & 0.1 \\
\hline Nitrates & $217(3.8)$ & $6(5)$ & 0.6 \\
\hline Depressed mood most or all of the time & $171(3.0)$ & $5(4)$ & 0.5 \\
\hline Mean (SD) calcium intake (mg) & $735(465)$ & $408(391)$ & 0.3 \\
\hline Mean (SD) vitamin D intake (IU) & $431(409)$ & & 0.4 \\
\hline ACEang) & & & \\
\hline
\end{tabular}

$\mathrm{ACE}=$ angiotensin converting enzyme; $\mathrm{SSR}=$ selective serotonin reuptake inhibitor.

*For differences in rib fracture case status by $x^{2}$ or Fisher's exact test for categorical variables, two sided $t$ tests for normally distributed continuous variables, and Wilcoxon rank-sum test for skewed continuous variables.

$\mathrm{P}=0.08$; statins $32 \%$ of cases $v 26 \%$ of non-cases, $\mathrm{P}=0.10$ ) (table 4). We found no significant differences in incident rib fracture by clinic site, race/ethnicity, marital status, education, self reported overall health, depressed mood, alcohol use, cigarette smoking, physical activity, hours of the day spent sitting, calcium and vitamin D intake, or family history of fracture or osteoporosis.

Although overall incidence of rib fracture was approximately 3/1000 person years, several groups had higher crude incidences (table 5). For example, men aged 80 or above had nearly twice the crude rate of men under 80 (5.55/1000 v3.09/1000 person years), and men with a history of rib fracture at baseline had an incidence of 7.78/1000 compared with an incidence of $2.75 / 1000$ among those without such a fracture history. Both of these risk factors were also fairly prevalent (about 15\% of the cohort), in comparison with, for example, Parkinson's disease, which coincided with an incidence of 11.92/1000 person years but was reported by only $0.8 \%$ of participants. In analyses adjusted for age alone, baseline factors associated with an increased risk of incident rib fracture included age more than 80 years, low hip bone mineral density, personal history of rib fracture or any fracture after age 50, a fall in the previous year, poor grip strength, and difficulties with instrumental activities of daily living. Arthritis was associated with a reduced risk of rib fracture. In analyses adjusted for age and bone mineral density, results were similar except that osteoporosis and a history of Parkinson's disease were no longer significant when bone mineral density was included in the model.

Table 6 shows the multiply adjusted risk factors for incident rib fracture with and without exclusion of bone mineral density in the model. In this analysis, a baseline history of rib fracture was the strongest risk factor for a new rib fracture: the more than 2.5-fold increased hazard ratio was slightly increased after exclusion of baseline hip bone mineral density. Other factors independently associated with new rib fractures were lower hip bone mineral density, age 80 or older, and difficulty with instrumental activities of daily living. Arthritis was associated with a nearly $40 \%$ reduced risk of rib fracture before and after exclusion of bone mineral density. Weight and a history of Parkinson's disease or cancer were independent risk factors for a new rib fracture only when bone mineral density was excluded from variable selection (table 6, model 2).

Figure 2 shows the multivariate model for history of rib fracture at baseline as a predictor of a new hip fracture $(\mathrm{n}=103)$, wrist fracture $(\mathrm{n}=56)$, rib fracture $(\mathrm{n}=126)$, or any clinical non-spine fracture $(\mathrm{n}=522)$ outcome. A history of rib fracture at baseline predicted a more than twofold increased risk of incident rib fracture (multivariable adjusted hazard ratio 2.71, 95\% confidence interval 1.86 to 3.95 ) and a twofold increased risk of fracture of the hip $(2.05,1.33$ to 3.15$)$ or wrist $(2.06$, 1.14 to 3.70). The risk for all non-spine fractures combined (which included fingers and toes) was also increased (adjusted hazard ratio $1.85,1.52$ to 2.26). Including bone mineral density in these models attenuated the risk by less than $4 \%$ (data not shown).

In a sensitivity analysis, in which we excluded 396 men with other (non-rib) fractures, the results were similar to the above findings. After exclusion of these other cases, the adjusted hazard ratio was 2.87 (1.97 to 4.18), compared with adjusted hazard ratio for the total cohort of 2.71 (1.86 to 3.95). In another sensitivity analysis, when we considered all self reported rib fractures instead of only those that were adjudicated by a physician, 47 additional participants were considered cases, and associations were slightly attenuated. The adjusted hazard ratio for a history of rib fracture was 2.47 (1.78 to 3.43$)$.

Only hip bone mineral density and old age were stronger predictors of hip fracture (hazard ratio 3.23, 2.59 to 4.02 , per standard deviation decrease in bone

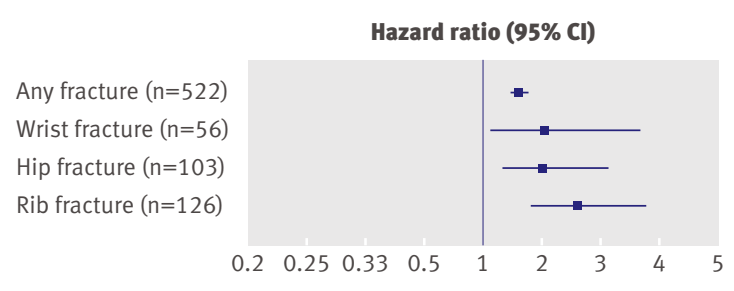

Fig 2 Adjusted hazard ratio and $95 \%$ confidence interval for baseline history of rib fracture $(n=5879)$ in MrOS Study.

Adjusted for hip bone mineral density, age $\geq 80$, arthritis, and difficulty with five instrumental activities of daily living.

Among all locations for a non-spine fracture combined, eight fracture locations accounted for $70 \%$ of fractures: 106 first incident fractures occurred in the rib, 85 in the hip, 54 at the ankle, 29 at the wrist, 29 at the clavicle, 28 in the arm, 28 in the foot, and 24 in the fingers. Adjusted hazard ratios were $1.85(95 \% \mathrm{Cl} 1.52$ to 2.26$)$ for any fracture, 2.06 (1.14 to 3.70) for wrist fracture, 2.05 (1.33 to 3.15) for hip fracture, and 2.71 (1.86 to 3.95$)$ for rib fracture 
Table $5 \mid$ Risk of rib fracture by selected baseline risk factors (6.2 years' mean follow-up on 5879 men aged 65 and over): MrOS Study

\begin{tabular}{lcccc} 
Risk factor & $\begin{array}{c}\text { Percent of } \\
\text { participants }\end{array}$ & $\begin{array}{c}\text { No of fractures } \\
\text { (incidence } / 1000 \\
\text { person years) }\end{array}$ & $\begin{array}{c}\text { Age adjusted hazard } \\
\text { ratio }(95 \% \mathrm{Cl})\end{array}$ & $\begin{array}{c}\text { Age and BMD } \\
\text { adjusted hazard } \\
\text { ratio }(95 \% \mathrm{Cl})\end{array}$ \\
\hline Age $\geq 80$ years: & 82.4 & $94(3.09)$ & Reference & Reference \\
\hline No & 17.6 & $32(5.55)$ & $1.83(1.23$ to 2.73$)$ & $1.58(1.05$ to 2.37$)$ \\
\hline Yes & & &
\end{tabular}

Previous fracture at any

age:

\begin{tabular}{lcccc}
\hline No & 45.0 & $30(2.58)$ & Reference & Reference \\
\hline Yes & 55.0 & $73(4.22)$ & $1.66(1.15$ to 2.41$)$ & $1.53(1.05$ to 2.22$)$ \\
\hline $\begin{array}{l}\text { Previous fracture at age } \\
\geq 50:\end{array}$ & & & & \\
\hline No & 77.9 & $76(2.69)$ & Reference & Reference \\
\hline Yes & 22.1 & $50(6.37)$ & $2.34(1.63$ to 3.34$)$ & 2.10 (1.47 to 3.02) \\
\hline
\end{tabular}

Previous rib fracture at

any age:

\begin{tabular}{lllcc}
\hline No & 85.4 & $85(2.75)$ & Reference & Reference \\
\hline Yes & 14.6 & $41(7.78)$ & $2.90(2.00$ to 4.21$)$ & 2.65 (1.82 to 3.86) \\
\hline
\end{tabular}

Previous rib fracture at

age $\geq 50$ :

\begin{tabular}{lcccc}
\hline No & 92.9 & $109(3.24)$ & Reference & Reference \\
\hline Yes & 7.1 & $17(6.85)$ & $2.11(1.27$ to 3.52$)$ & $1.95(1.17$ to 3.25$)$ \\
\hline $\begin{array}{l}\text { Osteoporosis: } \\
\text { No }\end{array}$ & 98.0 & $120(3.38)$ & Reference & Reference \\
\hline Yes & 2.0 & $6(8.57)$ & $2.39(1.05$ to 5.44$)$ & $1.83(0.80$ to 4.22$)$ \\
\hline Parkinson's disease: & & & & \\
\hline No & 99.2 & $123(3.42)$ & Reference & Reference \\
\hline Yes & 0.8 & $3(11.92)$ & $3.47(1.11$ to 10.9$)$ & $2.88(0.91$ to 9.07$)$ \\
\hline Arthritis: & & & & Reference \\
\hline No & 52.8 & $79(4.11)$ & Reference & \\
\hline Yes & 47.3 & $47(2.77)$ & $0.66(0.46$ to 0.94$)$ & $0.68(0.48$ to 0.98$)$ \\
\hline Cancer: & & & & Reference \\
\hline No & 71.2 & $80(3.08)$ & Reference & $1.35(0.94$ to 1.95$)$ \\
\hline Yes & 28.9 & $46(4.49)$ & $1.40(0.97$ to 2.01$)$ & \\
\hline
\end{tabular}

\section{Any falls in previous}

year:

\begin{tabular}{lllcc}
\hline No & 79.2 & $89(3.09)$ & Reference & Reference \\
\hline Yes & 20.9 & $37(5.01)$ & $1.56(1.06$ to 2.29$)$ & $1.54(1.05$ to 2.26$)$ \\
\hline
\end{tabular}

Grip strength quarter:

\begin{tabular}{lllcc}
\hline 1 & 25.3 & $43(5.03)$ & Reference & Reference \\
\hline 2 & 24.4 & $31(3.51)$ & $0.75(0.47$ to 1.20$)$ & $0.78(0.49$ to 1.25$)$ \\
\hline 3 & 24.7 & $21(2.31)$ & $0.51(0.30$ to 0.87$)$ & $0.55(0.32$ to 0.94$)$ \\
\hline 4 & 25.6 & $31(3.20)$ & $0.73(0.45$ to 1.18$)$ & $0.85(0.52$ to 1.39$)$
\end{tabular}

\begin{tabular}{lcccc}
\hline a blocker use: & & & & \\
\hline No & 84.8 & $100(3.25)$ & Reference & Reference \\
\hline Yes & 15.2 & $26(4.79)$ & $1.45(0.94$ to 2.24$)$ & 1.49 (0.97 to 2.30) \\
\hline Statin use: & & & & \\
\hline No & 74.1 & $86(3.20)$ & Reference & Reference \\
\hline Yes & 25.9 & $40(4.31)$ & $1.38(0.95$ to 2.00$)$ & 1.43 (0.98 to 2.09) \\
\hline
\end{tabular}

$\mathrm{BMD}=$ bone mineral density.

\section{Circumstances leading to rib fracture}

Only four incident rib fractures occurred in the absence of trauma, and they were first manifest as rib pain. Most incident fractures followed a fall, nearly half after a fall from a standing height (61 men; 48\%); 10\% (12 men) after a fall from a stair, step, or kerb; and 13\% (17 men) after a fall from more than this height. Ten men reported minimum or moderate trauma other than a fall; 22 men (17\%) reported severe trauma other than a fall, mainly vehicle accidents as passenger or pedestrian. Only three men reported more than one incident rib fracture on the same date (compatible with major trauma); only six men had a new rib fracture on more than one date.

Rib fractures after falls from a standing height included indoor falls (most often in the bedroom or bathroom at night) and outdoor seasonal falls associated with ice or snow. In a few cases, falls from a standing height involved strenuous sporting activities such as tennis or downhill skiing.

\section{Treatment for osteoporosis after rib fracture}

Overall, 82 men who had an incident rib fracture attended a follow-up MrOS visit or answered an interim questionnaire on drugs an average of 2.0 years (range 19 days to 5.3 years) after their incident rib fracture. Four of these men had $t$ scores below -2.5 , and 34 had a $t$ score between -2.5 and -1.0 , so that a total of 38 men might have been considered for osteoporosis treatment on the basis of the $t$ score alone; only 10 of these 38 men and 14 of all 82 men reported having begun bone specific prescription drugs.

\section{DISCUSSION}

The incidence of rib fracture was 3.5 per 1000 person years. Independent risk factors for an incident rib fracture (which represented 24\% of all incident non-spine fractures) were age 80 or over, low bone mineral density, difficulty with instrumental activities of daily living, and a baseline history of rib or chest fracture. A history of rib or chest fracture carried at least a twofold increased risk of an incident rib fracture, hip fracture, or wrist fracture. Only a minority of men reported treatment with bone specific drugs after their incident rib fracture.

\section{Comparison with other studies}

Surprisingly little attention has been paid to the causes or consequences of rib fractures, which are not mentioned in classic old or new publications or in the index of the Marcus textbook on osteoporosis. ${ }^{14-16}$ Most of the old literature on rib fractures was based on case series of patients, which did not permit the calculation of incidences or hazard ratios. ${ }^{1-5}$

Our study confirms an earlier study showing that rib fractures are the most common clinical fractures in older people, ${ }^{3}$ as well as a few earlier papers (published after dual photon or dual energy $x$ ray absorptiometry was available) noting that patients with rib fractures had lower bone density and suggesting that rib was a history of rib fracture (hazard ratio $2.05,1.33$ to 3.15). In contrast, bone mineral density and old age had weaker associations with incident wrist (hazard ratio $1.77,1.33$ to 2.35 per standard deviation decrease in bone mineral density and $1.13,0.59$ to 2.17 for age $\geq 80$ ) than did a history of rib fracture $(2.06,1.14$ to 3.70$)$. 
Table 6 | Multivariate adjusted models of risk factors for rib fracture including bone mineral density (BMD) in variable selection in 5879 men aged 65 and over (MrOS Study). Values are hazard ratios $(95 \% \mathrm{Cl})$

\begin{tabular}{lcc} 
& $\begin{array}{c}\text { Model 1: Including BMD } \\
\text { in variable selection }\end{array}$ & $\begin{array}{c}\text { Model 2: Excluding BMD } \\
\text { in variable selection }\end{array}$ \\
\hline Total hip BMD per SD decrease & $1.43(1.19$ to 1.73$)$ & NA \\
\hline Weight per SD decrease & $*$ & $1.23(1.01$ to 1.49$)$ \\
\hline Age $\geq 80$ years & $1.59(1.05$ to 2.39$)$ & $1.55(1.02$ to 2.35$)$ \\
\hline Difficulty with 5 IADLs (score) & $1.15(1.05$ to 1.25$)$ & $1.16(1.06$ to 1.27$)$ \\
\hline Rib fracture at any age & $2.71(1.86$ to 3.95$)$ & $3.01(2.07$ to 4.38$)$ \\
\hline Arthritis & $0.59(0.41$ to 0.85$)$ & $0.57(0.40$ to 0.83$)$ \\
\hline Parkinson's disease & $*$ & $3.33(1.05$ to 10.5$)$ \\
\hline History of cancer & $*$ & $1.45(1.01$ to 2.09$)$
\end{tabular}

IADLs=instrumental activities of daily living; NA=not applicable.

*In model 1, weight and history of Parkinson's disease and cancer were not selected.

fractures can be considered to be osteoporotic fractures. ${ }^{12}$

These results differ from those of European Prospective Osteoporosis Study, which showed no association of a history of rib fracture with future risk of fracture in men. ${ }^{5}$ The men studied were about 10 years younger than men included in the MrOS Study; only 135 men had a history of rib fracture (compared with 860 in our study), which may explain this difference, in that being aged 80 or older was a strong risk factor for incident rib fracture in the MrOS cohort.

Almost half of the rib fractures here followed a fall from a standing height. Similarly, the Study of Osteoporotic Fractures in community dwelling older women found that more than half of minimum trauma rib fractures followed a fall from a standing height. ${ }^{17}$

If rib fracture is due to osteoporosis and predicts future fracture, this missed diagnosis is a missed opportunity for intervention. In this study, less than one in five men reported any follow-up drug treatment for their radiographically confirmed rib fracture.

\section{Strengths and limitations of study}

Our study has several strengths. Rib fractures were the most common clinical fractures occurring during follow-up, providing adequate power to show statistically significant independent associations between history of rib fracture and incident fractures. The 99\% response rate (by survivors) to a query every four months about fractures is unique and makes it less likely that rib fractures would have been forgotten than in other reports in which rib fractures were

\section{WHAT IS ALREADY KNOWN ON THIS TOPIC}

Rib fractures are the most common clinical fracture in older men

\section{WHAT THIS STUDY ADDS}

Men with a previous rib fracture were older and had lower bone mineral density, more falls, and more impaired activities of daily living than did men without a history of rib fracture

They had a significantly increased risk of a new radiologically confirmed fracture at the hip, wrist, or rib independent of multiple other risk factors ascertained once a year at best. All incident fractures were validated, but rib fractures that did not lead to a radiograph would have been missed, because only rib fractures confirmed by radiology reports were included here. In our sensitivity analysis that included all self reported rib fractures, hazard ratios were similar to those in the main analysis of adjudicated fractures only, and conclusions remained the same. Nevitt et al reported a low accuracy of self reported rib fractures in older community dwelling women in the Study of Osteoporotic Fractures, such that about a quarter of self reported rib fractures were false positives. ${ }^{18}$ Likewise, $27 \%$ of self reported rib fractures in this study were not subsequently adjudicated as rib fractures. Such misclassification of the baseline rib fracture history, which was not validated, would have led to a conservative bias. One advantage to the earlier studies of patients in hospital is that they all had a definite diagnosis of rib fracture, but hospital admission for rib fractures surely reflects only the tip of the iceberg.

To our knowledge, no data exist on the frequency of undiagnosed rib fractures in community dwelling adults in the United States or elsewhere, because an unknown proportion of those who have sustained a rib fracture do not seek medical care and another unknown proportion of those who seek medical attention do not have a radiograph. The questionnaire mailed every four months also asked about falls, which are likely to be forgotten unless they led to injury, and about the circumstances of the falls, which have not been reported in other papers.

Limitations of the study should be noted. Some classification error is likely for the unvalidated baseline rib fracture history, but selective recall bias or misclassification of baseline covariates is less likely because this is a prospective study. No long term consequences of rib fracture beyond future risk of fracture were captured, nor do we have data on hospital admissions associated with isolated rib fractures. Barnea followed 77 women aged 65 and older who had been admitted to hospital for isolated rib fractures; the number of fractured ribs was correlated with morbidity and mortality over the next nine years. ${ }^{19}$ These women were likely to have been frail or otherwise ill, as most rib fractures do not lead to hospital admission even in elderly people. In our cohort study, only three men had more than one rib fracture on a single day.

\section{Conclusions and policy implications}

Rib fracture, the most common incident clinical fracture in older men, was associated with several classic risk markers for osteoporosis, including old age, low hip bone mineral density, and history of fracture. A history of rib fracture predicted a more than twofold increased risk of future fracture of the rib, hip, or wrist, independent of other covariates. Rib fracture should be considered to be an osteoporotic fracture when older men are evaluated for treatment to prevent future fracture. 
Contributors: $E B-C$ conceived and designed the study and was involved in analysis and interpretation of data, drafting and revising the manuscript for important intellectual content, coordination of revisions, and final approval of the submitted manuscript. CMN was involved in data analysis and interpretation and in writing and revising the manuscript. EO and DCB were involved in data interpretation and revising the manuscript. JAC was involved in data interpretation and in writing and revising the manuscript EB-C is the guarantor

Funding: The Osteoporotic Fractures in Men (MrOS) Study is supported by National Institutes of Health funding. The National Institute of Arthritis and Musculoskeletal and Skin Diseases (NIAMS), the National Institute on Aging (NIA), the National Center for Research Resources (NCRR), and NIH Roadmap for Medical Research provide support under the following grant numbers: U01 AR45580, U01 AR45614, U01 AR45632, U01 AR45647, U01 AR45654, U01 AR45583, U01 AG18197, U01-AG027810, and UL RR024140.

Competing interests: None declared.

Ethical approval: The institutional review board at each participating centre approved the study protocols. Participants provided written informed consent.

Data sharing: MrOS technical appendix, statistical code, and dataset are maintained at the Bone and Mineral Unit, Oregon Health and Science University, Portland, OR, and are available from CMN ( nielsoca@ohsu.edu).

1 Honkanen R, Kroger H, Tuppurainen M, Alhava E, Saarikoski S. Fractures and low axial bone density in perimenopausal women. J Clin Epidemiol 1995;48:881-8.

2 Davie M. Fractures at specific sites indicate low bone mineral density at lumbar spine and femoral neck in women. Journal of Orthopaedic Rheumatology 1996;9:41-5.

3 Jones G, Nguyen T, Sambrook PN, Kelly PJ, Gilbert C, Eisman JA. Symptomatic fracture incidence in elderly men and women: the Dubbo Osteoporosis Epidemiology Study (DOES). Osteoporos Int 1994;4:277-82.

4 Palvanen M, Kannus P, Niemi S, Parkkari J. Hospital-treated minimaltrauma rib fractures in elderly Finns: long-term trends and projections for the future. Osteoporos Int 2004;15:649-53.

5 Ismail AA, Silman AJ, Reeve J, Kaptoge S, O'Neill TW. Rib fractures predict incident limb fractures: results from the European prospective osteoporosis study. Osteoporos Int 2006;17:41-5.
6 Blank JB, Cawthon PM, Carrion-Petersen ML, Harper L, Johnson JP, Mitson E, et al. Overview of recruitment for the osteoporotic fractures in men study (MrOS). Contemp Clin Trials 2005;26:557-68.

7 Orwoll E, Blank JB, Barrett-Connor E, Cauley J, Cummings S, Ensrud K, et al. Design and baseline characteristics of the osteoporotic fractures in men (MrOS) study-a large observational study of the determinants of fracture in older men. Contemp Clin Trials 2005;26:569-85.

8 Adler NE, Epel ES, Castellazzo G, Ickovics JR. Relationship of subjective and objective social status with psychological and physiological functioning: preliminary data in healthy white women. Health Psychol 2000;19:586-92.

9 Washburn RA, Smith KW, Jette AM, Janney CA. The physical activity scale for the elderly (PASE): development and evaluation. J Clin Epidemiol 1993;46:153-62.

10 Block G, Hartman AM, Naughton D. A reduced dietary questionnaire: development and validation. Epidemiology 1990;1:58-64.

11 Pahor M, Chrischilles EA, Guralnik JM, Brown SL, Wallace RB, Carbonin P. Drug data coding and analysis in epidemiologic studies. Eur J Epidemiol 1994;10:405-11.

12 Sanders KM, Pasco JA, Ugoni AM, Nicholson GC, Seeman E, Martin TJ, et al. The exclusion of high trauma fractures may underestimate the prevalence of bone fragility fractures in the community: the Geelong Osteoporosis Study. J Bone Miner Res 1998;13:1337-42.

13 Mackey DC, Lui LY, Cawthon PM, Bauer DC, Nevitt MC, Cauley JA, et al. High-trauma fractures and low bone mineral density in older women and men. JAMA 2007;298:2381-8.

14 Cooper C, Melton LJ 3rd. Epidemiology of osteoporosis. Trends Endocrinol Metab 1992;3:224-9.

15 Kanis JA, Johnell O, Oden A, Johansson H, McCloskey E. FRAX and the assessment of fracture probability in men and women from the UK. Osteoporos Int 2008;19:385-97.

16 Marcus R, ed. Osteoporosis. Third ed. Elsevier, 2008.

17 Nevitt M, Cummings SR. Falls and fractures in older women. In: Falls, balance and gait disorders in the elderly: proceedings of the international symposium "Falls in the Elderly," Madrid, September 10, 1991. Elsevier, 1992.

18 Nevitt MC, Cummings SR, Browner WS, Seeley DG, Cauley JA Vogt TM, et al. The accuracy of self-report of fractures in elderly women: evidence from a prospective study. Am J Epidemiol 1992;135:490-9.

19 Barnea Y, Kashtan H, Skornick Y, Werbin N. Isolated rib fractures in elderly patients: mortality and morbidity. Can J Surg 2002;45:43-6.

Accepted: 14 November 2009 